OPEN ACCESS

Edited by:

Carlos Roncero,

Complejo Hospitalario de Salamanca,

Spain

Reviewed by:

Nelson Feldman,

Geneva University Hospitals (HUG),

Switzerland

Felix Henrique Paim Kessler,

Universidade Federal do Rio Grande

do Sul (UFRGS), Brazil

*Correspondence: Jessica Delorme

jdelorme@chu-clermontferrand.fr

Specialty section:

This article was submitted to Addictive Disorders,

a section of the journal

Frontiers in Psychiatry

Received: 29 March 2018

Accepted: 02 July 2018

Published: 23 July 2018

Citation:

Delorme J, Chenaf C, Bertin C, Riquelme M, Eschalier A, Ardid D and

Authier N (2018) Chronic Pain Opioid-Maintained Patients Receive Less Analgesic Opioid Prescriptions.

Front. Psychiatry 9:335

doi: 10.3389/fpsyt.2018.00335

\section{Chronic Pain Opioid-Maintained Patients Receive Less Analgesic Opioid Prescriptions}

\author{
Jessica Delorme ${ }^{1,2 *}$, Chouki Chenaf ${ }^{1,2}$, Celian Bertin ${ }^{1,2}$, Marie Riquelme ${ }^{1,2}$, \\ Alain Eschalier ${ }^{1,3}$, Denis Ardid ${ }^{1,3}$ and Nicolas Authier ${ }^{1,2,3}$ \\ ${ }^{1}$ Université Clermont Auvergne, CHU Clermont-Ferrand, Inserm, Neuro-Dol, Service de Pharmacologie médicale, Centres \\ Addictovigilance et Pharmacovigilance, Centre Evaluation et Traitement de la Douleur, Clermont-Ferrand, France, \\ ${ }^{2}$ Observatoire Français des Médicaments Antalgiques/French Monitoring Centre for Analgesic Drugs, Université Clermont \\ Auvergne - CHU Clermont-Ferrand, Clermont-Ferrand, France, ${ }^{3}$ Faculté de Médecine, Institut Analgesia, Clermont-Ferrand, \\ France
}

Treating pain and opioid use disorder represents a clinical challenge. While most studies that have assessed opioid analgesic use in opioid substitution treatment (OST) patients primarily address opioid analgesic misuse $(1,2)$, only few studies focused on OST patients assessed the prescription of analgesic opioids for chronic pain. We sought to compare the prevalence of analgesic opioid prescription (AOP) in two groups of chronic non-cancer pain (CNCP) patients: OST patients vs. the general population. This was a population-based cross-sectional study based on the French national healthcare claims database SNIIRAM (Système National d'Informations Inter-Régimes de l'Assurance Maladie) covering over 66 million people (98.8\% of the French population). Overall, 67,173 participants $\geq 15$ years old undergoing continuous OST in 2015 ("OST patients" group) were included and age- and gender-matched by means of a 1:1 ratio with 67,173 patients without OST ("control" group). In each group, patients with cancer conditions were excluded and those having received opioid and non-opioid analgesics for at least 3 months were identified (CNCP patients). Compared to control patients, CNCP OST patients received less AOP (47.8 vs. 68.0\%, $p<0.0001$ ) and more often non-opioid prescription (52.2 vs. $32.0 \%, p<0.0001$ ). In multivariate analysis, CNCP OST patients were 2.7 times less likely to be prescribed analgesic opioids (adjusted odds ratio [OR] $=$ 2.7 [2.42-3.01], $p<0.0001$ ) than control patients. AOP correlated in CNCP OST patients with: age $\leq 40$ years old, female gender, low-income status, methadone-maintained treatment, mental health disorder, hepatitis $\mathrm{C}$ virus $(\mathrm{HCV})$ infection, and alcohol abuse disorder. Opioid analgesics were less often prescribed in CNCP OST patients. AOP prevalence was 2.7-fold lower than in the general population. Chronic pain management in OST patients needs to be reinforced through additional physician training and a multidisciplinary approach.

Keywords: opioid analgesics, chronic non-cancer pain, opioid-maintained patients, methadone, buprenorphine 


\section{INTRODUCTION}

The use of analgesic opioids has dramatically increased over the last decade, particularly in North America, Europe, and Oceania (3-6). This increased prescription of analgesic opioids is partly related to the promotion of opioid use in chronic non-cancer pain (CNCP) management, despite the remaining controversy due to high-level scientific evidence demonstrating their weak long-term benefit (6-8). Worldwide, from 19 to $32 \%$ of general population suffered from chronic pain (9-15). Focusing on patients receiving opioid substitution treatment (OST), studies have revealed higher prevalence of chronic pain, reported in $29-68 \%$ of methadone patients (16-24) and $40-49 \%$ of buprenorphine patients $(19,23,25)$.

Treating both pain and addiction proves to be a significant challenge, and caregivers commonly report that all their diagnostic and therapeutic decisions are subject to ambiguity (26). While most studies examining opioid analgesic use in OST patients have addressed opioid analgesic misuse $(1,2)$, only few have specifically focused on OST patients who are prescribed analgesic opioids for chronic pain; the prevalence in this opioiddependent population of analgesic opioid prescription (AOP) ranged from 43 to $47 \%(17,21,27)$.

Pain management in OST patients is often stressful for primary care physicians (28), and they may be wary of prescribing opioid analgesics due to the potential risks of overdose $(3,29)$, diversion, and abuse (21). Inadequate AOP may both undertreat the pain and precipitate withdrawal symptoms (30). A recent study suggested that pain in methadone-maintained patients was undertreated: $54 \%$ of patients received no analgesic treatment, $24 \%$ analgesic opioids, and $22 \%$ non-opioid analgesics (31-33).

Furthermore, according to Whitehead et al. opioid prescriptions in patients with concomitant pain and substance abuse disorders were less frequent than in patients with pain only (34). As a result, OST patients are often unsatisfied with the insufficient healthcare they are receiving, which subsequently leads them to use licit or illicit opioids to relive their pain properly $(17,25,27,35)$.

This study sought to estimate and compare the prevalence of analgesic (opioid and non-opioid) prescription between CNCP OST patients and the non-opioid-dependent population with general CNCP, as well as to identify factors associated with AOP.

\section{METHODS}

\section{Design}

This was a population-based cross-sectional study using the French national claims database, SNIIRAM (Système National d'Informations Inter-Régimes de l'Assurance Maladie), covering almost 99\% of the French population (36). This database is completely anonymous and each patient has a unique anonymized identification number.

\section{Data}

The SNIIRAM database contains: (1) demographic data: gender, date of birth, information on the complementary private insurance coverage indicating low-income status; (2) presence of chronic disease, represented by a list of 30 long-term diseases (Affection Longue Durée [ALD]) with their associated ICD-10 (International Classification of Disease, version 10) codes; 3) medications, recorded as dispensed preparation packs including ATC (Anatomical Therapeutic Classification) codes, with pack descriptions including number of tablets, number of packs, dates of prescription and dispensation, as well as prescriber's specialty; (4) date and duration of hospital admissions, including both primary, related, and secondary diagnoses, with ICD-10 codes.

We were authorized to use the SNIIRAM database by the French national commission on information technologies and liberties (the French national data protection agency CNIL). As the SNIIRAM database is fully anonymized, no ethic committee approval is necessary.

\section{Participants}

We selected all opioid-maintained patients, male and female, aged $\geq 15$ years old, having received at least one OST prescription (methadone [MTD] or high-dose buprenorphine [HDB] \pm naloxone) between January 1st and December 31st 2015. Among these patients, those receiving continuous HDB or MTD treatment throughout 2015 were included, composing the "OST patients" group. Continuous treatment was defined as an interval between two consecutive dispensations $\leq 35$ days for HDB and MTD capsules and $\leq 18$ days for MTD syrup.

This 35-day threshold corresponded to the sum of the 28day maximum prescription duration for MTD capsule or HDB plus 7 days more to allow more precision for the identification of prescription interruption $(+25 \%$ of 28 days) $(37,38)$. Similarly, the 18-day threshold corresponded to the sum of the 14-day maximum prescription duration for MTD syrup plus 4 days more ( $+25 \%$ of 14 days). The "OST patients" group was age- and gender-matched on a 1:1 ratio with a control group constituted of male and female patients aged $\geq 15$ years old who had received no OST dispensation in 2015 ("General Population" control group). In each group, patients with cancer conditions were excluded and those treated continuously for at least 3 months with analgesics (interval between two consecutive opioid or non-opioid analgesic dispensations $\leq 45$ days) were defined as $\mathrm{CNCP}$ patients.

\section{Measures}

Several socio-demographic information were retrieved from this database: year of birth, gender, low-income status, and date of death. OST patients were selected through specific ATC codes: N07BC01, NO7BC51 for HDB and N07BC02 for methadone. Several comorbidities were recorded: human immunodeficiency virus (HIV) infection (ICD-10 code "B24"), hepatitis C virus (HCV) infection (ICD-10 codes "B182" and "B171"), and hepatitis B virus (HBV) infection (ICD10 codes "B180," "B181," and "B16"). Alcohol use disorder was identified either by a specific ICD-10 code ("F10") or at least one dispensation of acamprosate, disulfiram, or naltrexone (N07BB ATC code). Concomitant prescriptions of opioid analgesics were identified through specific ATC codes N02AA01 and N02AA51 (morphine), N02AB03 (fentanyl), N02AA05 and N02AA55 (oxycodone), N02AX02, and N02AX52 (tramadol), N02AA59 and N02AA79 (codeine), N02AA08, and 
N02AA58 (dihydrocodeine), N02AA02 (opium). Concomitant prescription of non-opioid analgesics included nefopam (ATC code N02BG06), paracetamol (N02BE01), non-steroidal anti-inflammatory drugs (M01A), and triptans (N02CC). ATC codes for psychotropic drugs were also recorded: N06A (antidepressants), N05A, except N05AN (antipsychotics), N05AN, N03AG01, and N03AG02 (mood stabilizers), N05B (anxiolytics), and N05C (hypnotics). The total quantity of analgesic opioids that were consumed was also calculated, each opioid converted to an oral morphine equivalent (OME) dose (39).

\section{Analyses}

Patients' characteristics were presented as mean \pm standard deviation [min-max] or as median [interquartile range] for continuous data and as the number of patients and associated percentages for categorical parameters. Comparisons of patient characteristics between the "CNCP OST patients" group and "the CNCP control" group were performed using the chi-squared test or the Fisher's test procedure test for categorical variables and $t$-test for quantitative variables, when appropriate.

To determine the influence of various factors associated with AOP in CNCP patients, a univariate logistic regression model was performed. The associated $p$-values were computed with their corresponding odds ratios (ORs) and their 95\% confidence intervals $(95 \% \mathrm{CI})$.

To study the risk factors associated with AOP, a multivariate logistic regression analysis was performed. All clinically-relevant variables or other variables associated with $p<0.25$ in univariate analysis were included in the model. The corresponding adjusted ORs were calculated with their 95\% CIs. A second univariate and multivariate analysis was then conducted to determine the factors associated with AOP in the subgroup of CNCP OST patients. SAS software for Windows Version 9.3 (SAS Institute, North Carolina, USA) was used for all statistical analyses.

\section{RESULTS}

We identified 67,173 patients continuously treated with OST (OST patients group) (67\% HDB and 33\% MTD) in 2015, ageand gender-matching them with 67,173 patients from the general population without OST or any diagnosed opioid abuse disorder (control group) (Figure 1). After matching, the mean age was $40.3 \pm 8.6$ years $[18-88]$ and the majority of patients were male (77.7\%). Overall, 8,499 and 1,989 CNCP patients were identified from the OST patients group and control group, respectively (12.6 vs. $3.0 \%, p<0.0001$ ).

\section{Patient Characteristics}

Compared to the CNCP control group (Table 1), CNCP OST patients were younger $(42.9 \pm 8.6$ yrs vs. $44.9 \pm 8.8$ yrs, $p<$ $0,0001)$, more frequently male (71.3 vs. $65.1 \%, p<0.0001)$, more frequently HIV-positive (2.4 vs. $1.0 \%, p<0.001)$ or HCV infected (7.5 vs. $0.5 \%, p<0.0001$ ), and more often exhibited alcohol use disorders ( 7.9 vs. $4.0 \%, p<0.0001)$ and mental health disorders (80.7 vs. $57.5 \%, p<0.0001)$. The prevalence of low-income status and $\mathrm{HBV}$ infection were not statistically different between the two groups.

The mean buprenorphine dose administered was significantly higher in CNCP OST patients than in non-CNCP OST patients $(11.3 \pm 11.5 \mathrm{mg}[0.1-296.6]$ vs. $9.2 \pm 9.3 \mathrm{mg}$ [0.1-237.3], $p<$ 0.0001 ), as was the mean methadone dose administered (syrup: CNCP OST: $59.8 \pm 36.9$ mg vs. non-CNCP OST: $52.7 \pm 30.5 \mathrm{mg}$, $p<0.0001$; capsule: CNCP OST: $61.2 \pm 49.1 \mathrm{mg}$ vs. non-CNCP OST: $53.6 \pm 45.2 \mathrm{mg}, p<0.0001)$.

\section{Opioid and Non-opioid Analgesic Prescription}

Compared to CNCP control patients, CNCP OST patients were significantly less likely to be prescribed opioid analgesics (47.8 vs. $68.0 \%, p<0.0001$ ), both in terms of strong opioids (4.6 vs. $8.5 \%, p<0.0001$, with less frequent prescription of fentanyl, morphine, and oxycodone) and weak opioid prescriptions (46.1 vs. $65.4 \%, p<0.0001$, with less frequent prescription of codeine, tramadol, and opium) (Table 2). The median OME cumulative dose was significantly greater in CNCP control patients than in CNCP OST patients (1800 mg [450-6768] vs. $968 \mathrm{mg}$ [300-4350], respectively, $p<0.0001)$.

Conversely, CNCP OST patients more often received nonopioid analgesics compared to CNCP control patients (52.2 vs. $32.0 \%, p<0.0001$ ), including more frequent prescriptions of NSAIDs, paracetamol, and nefopam. Triptans were less frequently employed in CNCP OST patients.

Different prescribers for OST and opioid analgesics were found in $81.7 \% \quad(82.9 \%$ for weak opioids and $98 \%$ for strong opioids) and $47.1 \%$ for OST and non-opioid analgesic prescription. Compared to CNCP control patients, CNCP OST patients received a lower median number of different opioid prescriptions [4 (1-11) vs. $6(2-12), p<0.0001]$.

\section{Factors Associated With Opioid Analgesic Prescription}

In univariate analysis, the factors associated with AOP were female gender (OR: 1.17 [95\% CI: 1.07-1.27]), alcohol use disorder (OR: 1.44 [1.24-1.67]), mental health disorder (OR: 1.32 [1.20-1.44]), and OST (OR: 2.32 [2.09-2.57]). Other covariates that were found to be significant at the $p<0.25$ level were: lowincome status (OR: 0.93 [0.85-1.02]), HCV infection (OR: 1.12 [0.95-1.31]), HIV infection (OR: 0.84 [95\% CI: 0.64-1.09]), and age $\leq 40$ years (OR: 1.05 [0.97-1.14]). Conversely, HBV infection (OR: 1.22 [95\% CI: 0.59-2.52], $p=0.59$ ), was not significantly associated with AOP.

On multivariate analysis (Figure 2), there was still significant correlation with age $\leq 40$ years (OR: 1.13 [1.04-1.23]), female gender (OR: 1.11 [1.02-1.20]), low-income status (OR: 0.87 [0.79-0.95]), mental health disorder (OR: 1.60 [1.46-1.76]), HCV infection (OR: 1.29 [1.09-1.52]), and alcohol use disorder (OR: 1.42 [1.22-1.65]). Compared to CNCP control patients, CNCP OST patients were 2.7 times less likely to be prescribed analgesic opioids (adjusted OR $=2.7[2.42-3.01]$ ). 


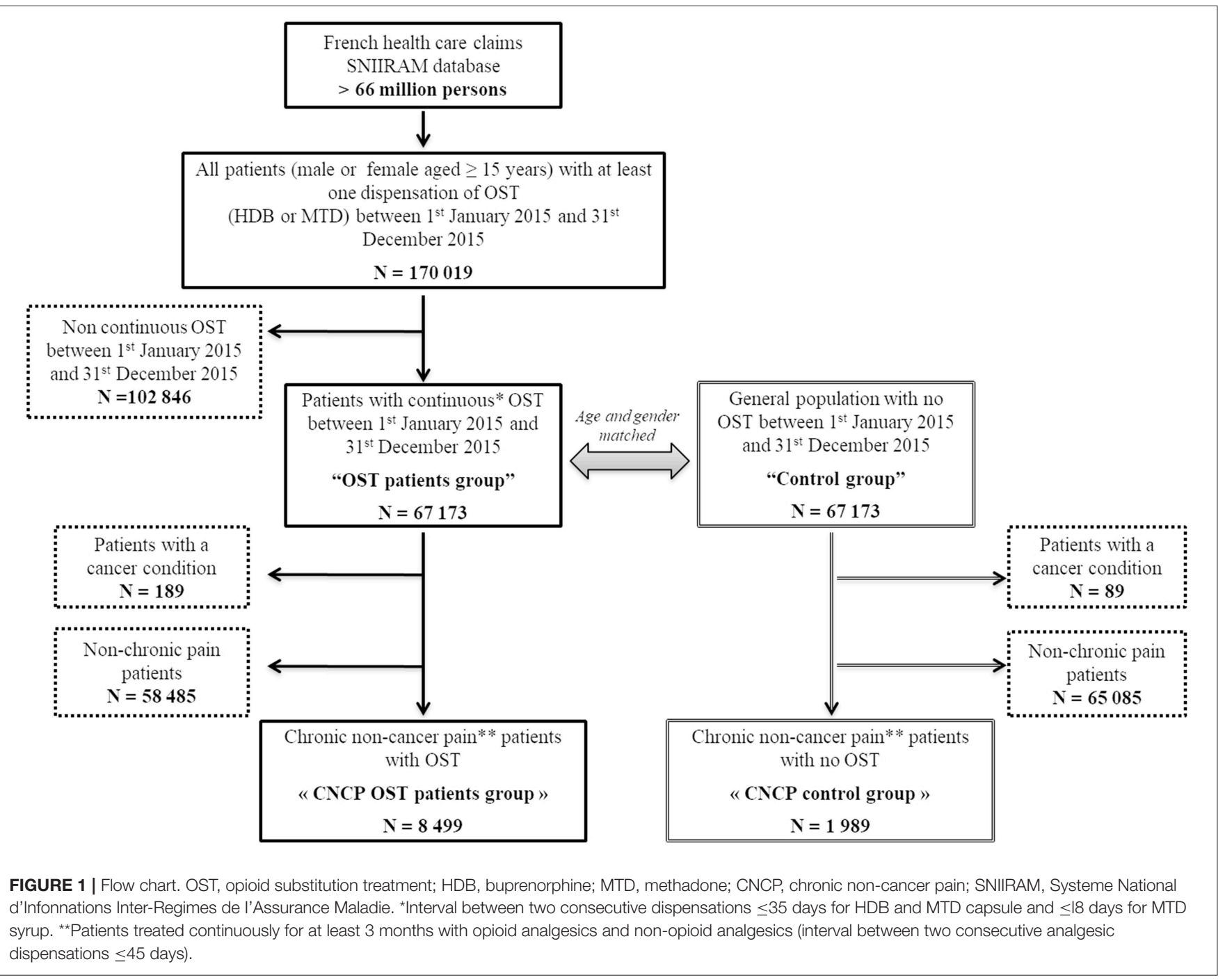

\section{Factors Associated With Opioid Analgesic Prescription in the Subgroup of CNCP OST Patients}

In multivariate analysis, age $\leq 40$ years (OR: 1.12 [1.02-1.22]), female gender (OR: 1.13 [1.03-1.24]), low-income status (OR: 0.85 [0.77-0.94]), methadone treatment (OR: 1.36 [1.23-1.50]), mental health disorder (OR: 1.49 [1.33-1.67]), HCV infection (OR: 1.21[1.02-1.43]), and alcohol use disorder (OR: 1.48 [1.26$1.74]$ ), were significantly correlated with AOP in chronic pain opioid-maintained patients (Figure 2).

\section{DISCUSSION}

To the best of our knowledge, the present nationwide study is the first that specifically compared opioid and non-opioid analgesic prescription in CNCP patients with or without OST. The prevalence of AOP was lower in the CNCP OST patients compared to CNCP control patients (47.8 vs. $68.0 \%)$. We observed similar prevalence of AOP in CNCP OST patients as that reported in prior studies, where prevalence ranged between 43 and $47 \%(17,21,27)$. Furthermore, following adjustment for age, gender, low-income status, mental health disorder, HCV infection, and alcohol use disorder, our findings revealed a 2.7-fold decrease in the prevalence of AOP in CNCP OST patients compared to CNCP control patients. Conversely, our study demonstrated analgesic non-opioids were more frequently administered in CNCP OST patients $(52.2 \%)$ compared to CNCP control patients $(32.0 \%)$. These findings were also consistent with prior studies, where this prevalence ranged from 48.9 to $64.1 \%$ in opioid-maintained patients $(17,25,27)$.

Overall, chronic pain opioid-maintained patients received less AOPs and a number of hypotheses may be assumed.

\section{Opiophobia}

The first hypothesis may be linked to the reluctance to prescribe analgesic opioids which is known as "opiophobia," 
TABLE 1 | Comparison of characteristics between CNCP OST patients group and CNCP control group in 2015.

\begin{tabular}{|c|c|c|c|}
\hline & $\begin{array}{l}\text { CNCP OST patients } \\
\text { group }\end{array}$ & $\begin{array}{l}\text { CNCP control } \\
\text { group }\end{array}$ & $P$-value \\
\hline & $\begin{array}{c}N=8,499 \\
\%(N)\end{array}$ & $\begin{array}{c}N=1,989 \\
\%(N)\end{array}$ & \\
\hline $\begin{array}{l}\text { Age (years), mean } \\
( \pm \mathrm{SD})\end{array}$ & $42.9 \pm 8.6$ & $44.9 \pm 8.8$ & $<0.0001$ \\
\hline \multicolumn{4}{|l|}{ AGE CLASS } \\
\hline$\leq 40$ & $37.9(3,218)$ & 30.6 (608) & $<0.0001$ \\
\hline$>40$ & $62.1(5281)$ & $69.4(1381)$ & \\
\hline Male gender & $71.3(6,059)$ & $65.1(1,295)$ & $<0.0001$ \\
\hline Low-income status & $23.7(2,017)$ & $25.7(511)$ & 0.07 \\
\hline HIV infection & $2.4(200)$ & $1.0(20)$ & 0.0002 \\
\hline HCV infection & $7.5(634)$ & $0.5(10)$ & $<0.0001$ \\
\hline HBV infection & $0.3(22)$ & $0.4(8)$ & 0.28 \\
\hline Alcohol use disorder & $7.9(670)$ & $4.0(79)$ & $<0.0001$ \\
\hline Mental health disorder & $80.7(6,857)$ & $57.5(1,143)$ & $<0.0001$ \\
\hline $\begin{array}{l}\text { Number of different } \\
\text { OST prescribers, } \\
\text { median [IQR] }\end{array}$ & $2[1-2]$ & - & - \\
\hline Buprenorphine & $68.9(5,857)$ & - & - \\
\hline $\begin{array}{l}\text { Buprenorphine } \pm \\
\text { naloxone }\end{array}$ & $4.1(346)$ & - & - \\
\hline Methadone & $30.9(2,617)$ & - & - \\
\hline Capsule & $66.5(1,510)$ & - & - \\
\hline Syrup & 33.5 (761) & - & - \\
\hline $\begin{array}{l}\text { Switch } \\
\text { buprenorphine/methadone }\end{array}$ & $0.2(25)$ & - & - \\
\hline
\end{tabular}

CNCP, chronic non-cancer pain; OST, opioid substitution treatment; HIV, human immunodeficiency virus; $H C V$, hepatitis $C$ virus; $H B V$, hepatitis B virus; IQR, interquartile range (25th and 75 th percentiles).

${ }^{a}$ Total number of different OST prescribers used by opioid-maintained patients during 2015.

and many caregivers refuse to prescribe opiates at all, or limit prescriptions so far as to never provide enough to effectively relieve pain, and this phenomena is widespread across the world (40-43). Recognizing the potential risk from opioids, an international committee of pain specialists including physicians and healthcare policy specialists concluded that "irrational fear of the drugs often impedes their appropriate use" (44). Many physicians have admitted they were uncomfortable with the safe prescription of opioids (28) and have questioned their own practice of analgesic opioid prescribing. There are several reasons why physicians might not prescribe analgesic opioids in OST patients.

First, the use of analgesic opioids in addition to an OST may result in opioid abuse disorder relapse. A recent study showed that the risk of reporting cravings in the preceding week was associated with a 3 -fold increase in chronic pain and characterized this population as potentially at risk of relapse (45). However, it is worth noting that underdiagnosed or undertreated pain could also result in an imbalance and even an aggravation of opioid abuse disorders.

Secondly, the increase of pain sensitivity (hyperalgesia) induced by long-term opioid use could also form a barrier
TABLE 2 | Comparison of analgesic drug prescription between chronic non-cancer pain opioid substitution treatment (CNCP OST) patients group and CNCP control group.

\begin{tabular}{|c|c|c|c|}
\hline & $\begin{array}{l}\text { CNCP OST patients } \\
\text { group }\end{array}$ & $\begin{array}{l}\text { CNCP control } \\
\text { group }\end{array}$ & $P$-value \\
\hline & $\begin{array}{c}N=8,499 \\
\%(N)\end{array}$ & $\begin{array}{c}N=1,989 \\
\%(N)\end{array}$ & \\
\hline Opioid analgesic use & $47.8(4,065)$ & $68.0(1,352)$ & $<0.0001$ \\
\hline Strong opioids & 4.6 (394) & 8.5 (169) & $<0.0001$ \\
\hline Fentanyl & $0.6(49)$ & $1.4(28)$ & $<0.0001$ \\
\hline Morphine & 3.2 (273) & $5.2(103)$ & $<0.0001$ \\
\hline Oxycodone & $1.3(106)$ & $3.4(67)$ & $<0.0001$ \\
\hline Weak opioids & $46.1(3,921)$ & $65.4(1,300)$ & $<0.0001$ \\
\hline Codeine & $19.0(1,618)$ & 32.1 (638) & $<0.0001$ \\
\hline Tramadol & $28.3(2,403)$ & 39.7 (790) & $<0.0001$ \\
\hline Opium & $13.0(1107)$ & $21.4(425)$ & $<0.0001$ \\
\hline $\begin{array}{l}\text { Exclusive non-opioid } \\
\text { analgesic use }\end{array}$ & $52.2(4,434)$ & $32.0(637)$ & $<0.0001$ \\
\hline NSAIDS & $35.8(3,044)$ & 20.7 (412) & $<0.0001$ \\
\hline Paracetamol & $48.0(4,073)$ & 29.1 (579) & $<0.0001$ \\
\hline Nefopam & $1.6(132)$ & $0.4(8)$ & $<0.0001$ \\
\hline Triptans & $8.1(687)$ & $10.0(200)$ & 0.004 \\
\hline
\end{tabular}

CNCP, chronic non-cancer pain; OST, opioid substitution treatment; NSAIDs, nonsteroidal anti-inflammatory drugs.

against opioid prescription in OST patients (46-48). An Australian study has demonstrated that methadone-maintained patients with chronic pain treated with analgesic opioids presented an hyperalgesia when submitted to the cold pressor test (48).

Thirdly, there is wide abuse in terms of diversion associated with analgesic opioids in OST patients, where pain may be reported solely to manipulate prescribers to obtain opioid medication. An American study showed that $57.5 \%$ of analgesic opioid misuse occurred in methadone-maintained patients with chronic pain (21). Two recent studies also highlighted that the major source of diverted opioids was physician prescriptions $(49,50)$.

Finally, some doctors may use methadone and buprenorphine both as substitution therapy and as analgesics. This may partly account for the lack of supplemental opioid analgesic prescription. Moreover it is well known that the concomitant use of high-dose analgesic opioids and OST can lead to increased risk of accidental and fatal overdoses (3, 29). Between 2013 and 2014 in the US, the synthetic opioids overdose-related deaths almost doubled (51). From 1999 to 2015, prescribed opioid overdoses involved more than 183,000 deaths in the U.S $(51,52)$. In OST patients, overdose mortality accounted for 12.7 overdose deaths per thousand people per year in the U.S.A. (53). The overdose risks are also related to the well acknowledged phenomenon of opioid tolerance that occurs when opioid analgesics are taken over an extended period of time. Patients with opioid tolerance actually require higher opioid dosages to achieve the same analgesic effect, which may 


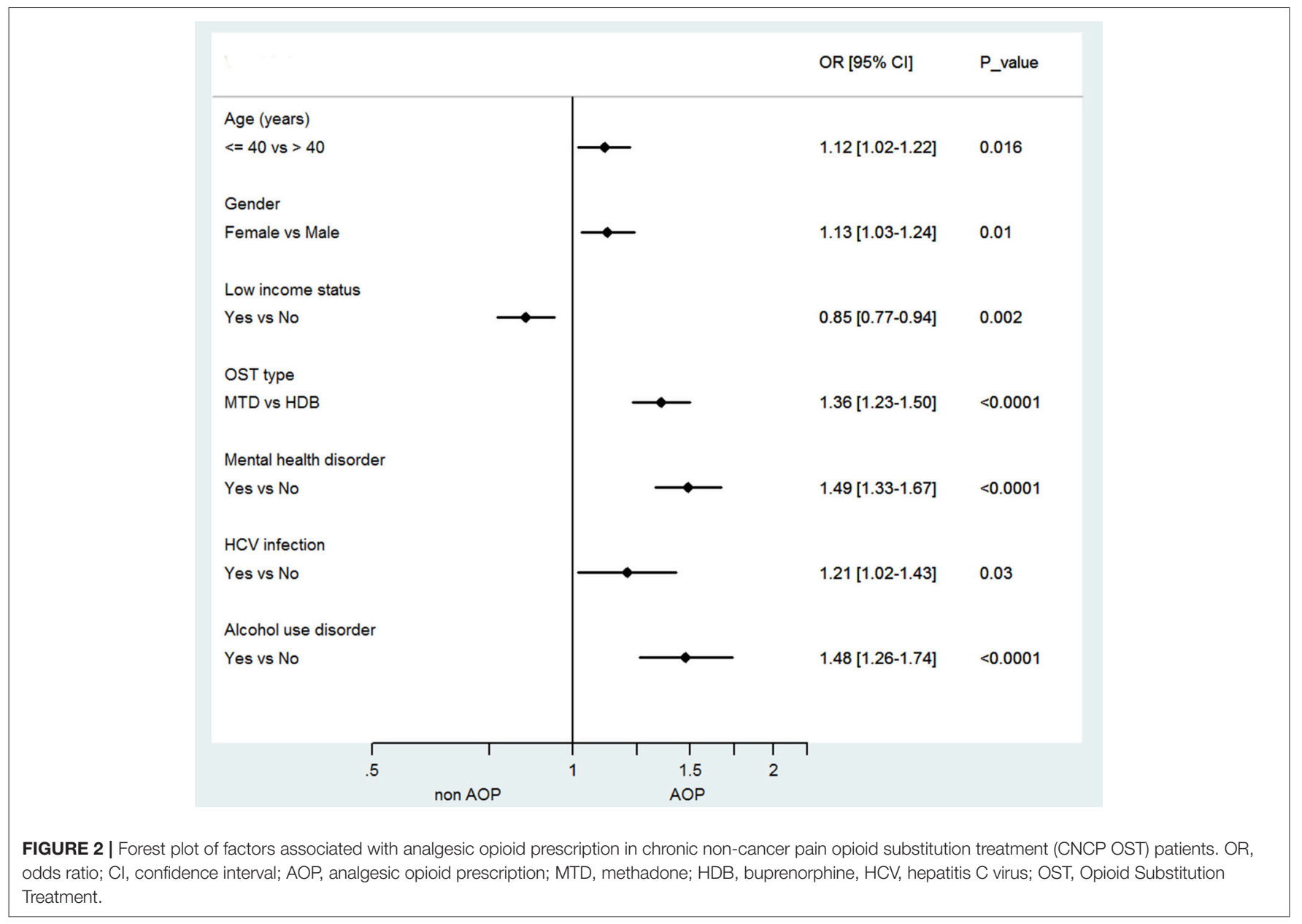

increase the risk of accidental overdoses (54-56). Consequently, these potential overdose risks may encourage doctors to avoid adding up opioid drugs or increasing opioid analgesic doses.

Non-or undertreated pain may have negative consequences, including searches for ways to manage pain illegally. Many studies have found that OST patients often felt that their pain was not well managed, and the absence of pain management encouraged them to use illicit opioids for pain relief (25, 27, 35). Many recent studies have reported OST patients using over-the-counter drugs (from 37.7 to 75\%) (17, 27), heroin (25\%) (27), and non-pharmacological strategies (19\% meditation, $12-18 \%$ relaxation) $(17,23)$ to relieve their pain themselves (19-22, 25, 27, 35, 57, 58). Chronic pain should be routinely assessed in OST patients since it constitutes a significant component in the global patient management. The lack of specific recommendations in the assessment and treatment of chronic pain in these patients makes a proper management more complex. It has now been recognized that clinicians require educating about this topic. Despite progress in their training, there are still misconceptions and fears that prevent clinicians from prescribing analgesic opioids in dependent patients that would indeed clearly benefit clinically (44).

\section{Factors Associated With Analgesic Opioids Prescriptions}

In multivariate analysis, our study identified several correlations with AOPs in OST patients: female gender, younger age, lowincome status, mental health disorder, $\mathrm{HCV}$ infection, alcohol use disorder, and MTD treatment. The literature has amply demonstrated that the prevalence of pain is higher in women than in men $(12,59-61)$. Similarly to our findings, Nosyk et al. found that female gender was associated with significantly higher odds AOP in methadone maintenance treatment $(\mathrm{OR}=1.42$ [1.31-1.55]) (62). Another recent study found that women were at higher risk of chronic analgesic opioid use following total hip arthroplasty (63). Disparities in healthcare have also been documented $(64,65)$, with patients of lower incomes more often reporting pain $(12,59,61,65)$ and developing substance abuse disorders (66). Several studies among HCV+ patients reported a high prevalence of pain in this population (34, 67, 68). An American study found that $\mathrm{HCV}+$ patients were frequently diagnosed with pain and substance abuse disorder and were frequently prescribed analgesic opioids (34). More recently, another study showed that the risk of chronic pain in $\mathrm{HCV}+$ patients was doubled (albeit non-significant) (69). Previous studies have identified associations between chronic pain and alcohol dependence $(70,71)$. According to a recent 
Australian study, "drinkers" took higher opioid doses, reported more multiple pain conditions, and had higher pain severity than "non drinkers" (70). Some studies reported that patients suffering from depression were more prone to receive chronic opioid therapy, suggesting that mental health disorder might represent a risk factor for opioid misuse (72-76). Grattan et al. reported that there was a 1.8- to 2.4-fold increased risk of opioid medication abuse in patients with depression (77). Moreover, it is well known that mental health disorders are classically associated with chronic pain in substance abuse disorders $(19,23,24,78)$. The coexistence of both a mental health disorder and substance abuse disorder is currently acknowledged to be a co-occurring disorder and refers to the concept of "dual diagnosis" $(79,80)$. Originally, since the $90 \mathrm{~s}$, the term of "triple diagnosis" has been recognized and arose from 1/ a "dual diagnosis", which is largely acknowledged in the psychiatry field, and refers to a patient with a severe mental illness and a substance use disorder, plus 2/ a "human immunodeficiency virus infection". Nevertheless, this term of "triple diagnosis" does not have a unique and generally agreed-upon usage since it has also been used in other settings: a few authors introduced the notion of chronic pain as a co-occurring disorder with the earlier "dual diagnosis". In our study, we are specifically referring to the very same latter meaning. Chronic pain adds a third potential clinical problem in OST patients with mental health disorders and represent the third pathologic dimension of the "triple diagnosis". These three pathological conditions are so closely intertwined that any positive progression or aggravation of one condition will affect the other two. Overall, this term emphasizes the need to consider treating a patient as a whole and not his component parts separately. The management of this "triple diagnosis" presents a considerable and real challenge for caregivers since its symptoms are often complex and severe.

In our study, $81 \%$ of OST patients were prescribed opioids by physicians other than their OST prescriber. These findings are in line with a recent study conducted among methadonemaintained patients, which found that $74 \%$ and $67.7 \%$ of opioid co-prescriptions with OST originated from non-methadone physicians $(62,81)$. The reasons behind this disproportion remains unclear; whether opioid prescriptions are obtained for legitimate pain conditions (e.g., dental procedures, chronic pain, trauma, or so on) or for non-medical reasons (e.g., abuse or diversion) cannot be definitively answered and needs further investigation.

\section{STRENGTHS AND LIMITATIONS}

This study represents an original approach in that it is the first to focus on OST patients whose CNCP was treated by analgesic opioids. Furthermore, we used the largest French continuous nationwide claims database (covering $99 \%$ of the French population), enabling an exhaustive identification of the OST population in France. Moreover, this is the first European study that provides valuable data about AOPs in OST patients, as France accounts for almost one quarter of all opioid-maintained patients in Europe. In addition, our findings contribute to current knowledge with specific data on prescribed analgesic opioids in CNCP buprenorphine-maintained patients, given that the majority of previous studies were carried out in methadonemaintained patients. Interestingly, unlike others countries, HDB is the most frequent prescribed OST in France, while MTD is the most common treatment elsewhere in Europe and the rest of the world.

Nevertheless, several limitations inherent to claims database are present. First, our data does not include detailed clinical information on for example, severity of addiction, other risks behaviors, or other detailed related to mental disorders that could prevent opioid prescription by doctors. Importantly, characteristics of chronic pain are lacking and particularly no information on pain intensity was available.

The main result of our study shows that OST patients were less frequently prescribed analgesic opioids, compared to a general chronic pain population, a result which may actually simply reflect more severe pain in the latter group. However, this seems unlikely since the literature widely reports higher prevalence of pain in patients with opioid use disorders (31-41 vs. 12$30 \%$ in the general population) $(15,16,24,27,82)$. In this context, we can reasonably assume that the underprescription of analgesic opioids in OST patients may be related to a reluctance of prescribers. In this context of inadequate pain relief, several studies have showed that a significant proportion of OST patients use street-bought or illicit drugs to effectively alleviate their pain.

\section{CONCLUSION}

AOPs were significantly less frequent and at lower dosages in CNCP OST patients compared to a CNCP control group. We proposed a number of hypotheses that might account for these differences, but we have to remain cautious since confounding bias cannot be totally ruled out. Proper management of patients with a "triple diagnosis" (mental disorders, addiction, and chronic pain), is challenging, and such patients should have access to a multidisciplinary care model thereby avoiding the socalled "wrong door syndrome." If undiagnosed or untreated, one of these conditions could result in an imbalance and even an aggravation of the other two. The real challenge in OST patients, therefore, is to guide the management of chronic pain through a multidisciplinary approach involving general practitioners, addictologists, psychiatrists, and pain specialists, all working in concert using a syndrome-based approach.

\section{ETHICS STATEMENT}

No ethic committee approval was necessary since this study used anonymized data from the French national claims database.

\section{AUTHOR CONTRIBUTIONS}

JD wrote the first draft of the manuscript. The data were analyzed by JD and MR. NA, AE, DA, CB and CC provided revision of the intellectual content and final approval of the manuscript. 


\section{REFERENCES}

1. Brands B, Blake J, Sproule B, Gourlay D, Busto U. Prescription opioid abuse in patients presenting for methadone maintenance treatment. Drug Alcohol Depend. (2004) 73:199-207. doi: 10.1016/j.drugalcdep. 2003.10.012

2. Rosenblum A, Parrino M, Schnoll SH, Fong C, Maxwell C, Cleland $\mathrm{CM}$, et al. Prescription opioid abuse among enrollees into methadone maintenance treatment. Drug Alcohol Depend. (2007) 90:64-71. doi: 10.1016/j.drugalcdep.2007.02.012

3. Dart RC, Surratt HL, Cicero TJ, Parrino MW, Severtson SG, BucherBartelson B, et al. Trends in Opioid Analgesic Abuse and Mortality in the United States. N. Engl. J. Med. (2015) 372:241-8. doi: 10.1056/NEJMsa 1406143

4. Fischer B, Nakamura N, Ialomiteanu A, Boak A, Rehm J. Assessing the prevalence of nonmedical prescription opioid use in the general Canadian population: methodological issues and questions. Can. J. Psychiatry Rev. Can. Psychiatr. (2010) 55:606-9. doi: 10.1177/07067437100 5500909

5. Kuehn BM. Opioid prescriptions soar: increase in legitimate use as well as abuse. JAMA (2007) 297:249-51. doi: 10.1001/jama.297.3.249

6. Manchikanti L, Helm S, Fellows B, Janata JW, Pampati V, Grider JS, et al. Opioid epidemic in the United States. Pain Physician (2012) 15, ES9-38.

7. Franklin GM. Opioids for chronic noncancer pain A position paper of the American Academy of Neurology. Neurology (2014) 83:1277-84. doi: 10.1212/WNL.0000000000000839

8. Nadeau SE. Opioids for chronic noncancer pain. Neurology (2015) 85:646-51. doi: 10.1212/WNL.0000000000001766

9. Bouhassira D, Lantéri-Minet M, Attal N, Laurent B, Touboul C. Prevalence of chronic pain with neuropathic characteristics in the general population. Pain (2008) 136:380-7. doi: 10.1016/j.pain.2007.08.013

10. Breivik H, Collett B, Ventafridda V, Cohen R, Gallacher D. Survey of chronic pain in Europe: prevalence, impact on daily life, and treatment. Eur. J. Pain Lond. Engl. (2006) 10:287-333. doi: 10.1016/j.ejpain. 2005.06.009

11. Fayaz A, Croft P, Langford RM, Donaldson LJ, Jones GT. Prevalence of chronic pain in the UK: a systematic review and meta-analysis of population studies. BMJ Open (2016) 6:e010364. doi: 10.1136/bmjopen-2015010364

12. Johannes CB, Le TK, Zhou X, Johnston JA, Dworkin RH. The prevalence of chronic pain in united states adults: results of an internet-based survey. J. Pain (2010) 11:1230-9. doi: 10.1016/j.jpain.2010.07.002

13. Nahin RL. Estimates of pain prevalence and severity in adults: United States, 2012. I Pain Off J Am Pain Soc. (2015) 16:769-80. doi: 10.1016/j.jpain.2015.05.002

14. Schopflocher D, Taenzer P, Jovey R. The prevalence of chronic pain in Canada. Pain Res Manag J Can Pain Soc. (2011) 16:445-50. doi: 10.1155/2011/ 876306

15. Steingrímsdóttir ÓA, Landmark T, Macfarlane GJ, Nielsen CS. Defining chronic pain in epidemiological studies - a systematic review and meta-analysis. Pain (2017) 158:2092-107. doi: 10.1097/j.pain.000000000 0001009

16. Barry DT, Beitel M, Garnet B, Joshi D, Rosenblum A, Schottenfeld RS. Relations among psychopathology, substance use, and physical pain experiences in methadone-maintained patients. J Clin Psychiatry (2009) 70:1213-8. doi: 10.4088/JCP.08m04367

17. Dhingra L, Masson C, Perlman DC, Seewald RM, Katz J, McKnight C, et al. Epidemiology of pain among outpatients in methadone maintenance treatment programs. Drug Alcohol Depend. (2013) 128:161-5. doi: 10.1016/j.drugalcdep.2012.08.003

18. Dunn KE, Brooner RK, Clark MR. Severity and interference of chronic pain in methadone-maintained outpatients. Pain Med. Malden Mass (2014) 15:1540-8. doi: 10.1111/pme.12430

19. Dunn KE, Finan PH, Tompkins DA, Fingerhood M, Strain EC. Characterizing pain and associated coping strategies in methadone and buprenorphine-maintained patients. Drug Alcohol Depend. (2015) 157:143-9. doi: 10.1016/j.drugalcdep.2015.10.018
20. Eyler ECH. Chronic and acute pain and pain management for patients in methadone maintenance treatment. Am J Addict Am Acad Psychiatr Alcohol Addict. (2013) 22:75-83. doi: 10.1111/j.1521-0391.2013.00308.x

21. Glenn MC, Sohler NL, Starrels JL, Maradiaga J, Jost JJ, Arnsten $\mathrm{JH}$, et al. Characteristics of methadone maintenance treatment patients prescribed opioid analgesics. Subst Abuse (2016) 37:387-91. doi: 10.1080/08897077.2015.1135225

22. Jamison RN, Kauffman J, Katz NP. Characteristics of methadone maintenance patients with chronic pain. J Pain Symptom Manage. (2000) 19:53-62. doi: 10.1016/S0885-3924(99)00144-X

23. Nielsen S, Larance B, Lintzeris N, Black E, Bruno R, Murnion B, et al. Correlates of pain in an in-treatment sample of opioid-dependent people. Drug Alcohol Rev. (2013) 32:489-94. doi: 10.1111/dar.12041

24. Voon P, Hayashi K, Milloy MJ, Nguyen P, Wood E, Montaner J, et al. Pain among high-risk patients on methadone maintenance treatment. J Pain Off $J$ Am Pain Soc. (2015) 16:887-94. doi: 10.1016/j.jpain.2015.06.003

25. Stein MD, Herman DS, Bailey GL, Straus J, Anderson BJ, Uebelacker LA, et al. Chronic pain and depressionamong primary care patients treated with buprenorphine. J Gen Intern Med. (2015) 30:935-41. doi: 10.1007/s11606-015-3212-y

26. Berg KM, Arnsten JH, Sacajiu G, Karasz A. Providers' experiences treating chronic pain among opioid-dependent drug users. J Gen Intern Med. (2009) 24:482-8. doi: 10.1007/s11606-009-0908-x

27. Rosenblum AJH. PRevalence and characteristics of chronic pain among chemically dependent patients in methadone maintenance and residential treatment facilities. JAMA (2003) 289:2370-8. doi: 10.1001/jama.289.18.2370

28. Keller CE, Ashrafioun L, Neumann AM, Van Klein J, Fox CH, Blondell RD. Practices, perceptions, and concerns of primary care physicians about opioid dependence associated with the treatment of chronic pain. Subst Abuse (2012) 33:103-13. doi: 10.1080/08897077.2011.630944

29. Webster LR, Cochella S, Dasgupta N, Fakata KL, Fine PG, Fishman SM, et al. An analysis of the root causes for opioid-related overdose deaths in the United States. Pain Med Malden Mass (2011) 12 (Suppl. 2):S26-35. doi: 10.1111/j.1526-4637.2011.01134.x

30. Donaher PA, Welsh C. Managing opioid addiction with buprenorphine. Am. Fam. Physician (2006) 73:1573-8.

31. Hines S, Theodorou S, Williamson A, Fong D, Curry K. Management of acute pain in methadone maintenance therapy in-patients. Drug Alcohol Rev. (2008) 27:519-23. doi: 10.1080/09595230802245519

32. Nordmann S, Vilotitch A, Lions C, Michel L, Mora M, Spire B, et al. Pain in methadone patients: Time to address undertreatment and suicide risk (ANRS-Methaville trial). PloS ONE (2017) 12:e0176288. doi: 10.1371/journal.pone.0176288

33. Rowley D, McLean S, O'Gorman A, Ryan K, McQuillan R. Review of cancer pain management in patients receiving maintenance methadone therapy. Am J Hosp Palliat Care (2011) 28:183-7. doi: 10.1177/1049909110380897

34. Whitehead AJ, Dobscha SK, Morasco BJ, Ruimy S, Bussell C, Hauser P. Pain, substance use disorders and opioid analgesic prescription patterns in veterans with hepatitis C. J Pain Symptom Manage. (2008) 36:39-45. doi: 10.1016/j.jpainsymman.2007.08.013

35. St Marie B. Health care experiences when pain and substance use disorder coexist: “just because i'm an addict doesn't mean i don't have pain." Pain Med. Malden Mass (2014) 15:2075-86. doi: 10.1111/pme.12493

36. Bezin J, Duong M, Lassalle R, Droz C, Pariente A, Blin P, et al. The national healthcare system claims databases in France, SNIIRAM and EGB: powerful tools for pharmacoepidemiology. Pharmacoepidemiol Drug Saf. (2017) 26:954-62. doi: 10.1002/pds.4233

37. Pauly V, Pradel V, Frauger E, Micallef J, Thirion X. Evolution of opioids reimbursement since 2004 from the National Database of the General Health Insurance System. Thérapie (2011) 66:369-72. doi: 10.2515/therapie/2011037

38. Pradel V, Frauger E, Thirion X, Ronfle E, Lapierre V, Masut A, et al. Impact of a prescription monitoring program on doctor-shopping for high dosage buprenorphine. Pharmacoepidemiol Drug Saf. (2009) 18:36-43. doi: $10.1002 /$ pds. 1681

39. Nielsen S, Degenhardt L, Hoban B, Gisev N. A synthesis of oral morphine equivalents (OME) for opioid utilisation studies. Pharmacoepidemiol Drug Saf. (2016) 25:733-7. doi: 10.1002/pds.3945 
40. Bruce RMJ. 'Opiophobia' Past and Present. Available online at: https:// www.practicalpainmanagement.com/treatments/pharmacological/opioids/ opiophobia-past-present (Accessed July 10, 2017) (2012)

41. Morgan JP. American opiophobia: customary underutilization of opioid analgesics. Adv Alcohol Subst Abuse (1985) 5:163-73. doi: 10.1300/J251v05n01_11

42. Motov SM, Khan AN. Problems and barriers of pain management in the emergency department: are we ever going to get better? J Pain Res. (2008) 2:5-11. Available online at: http://www.ncbi.nlm.nih.gov/pmc/articles/ PMC3004630/ (Accessed August 29, 2017).

43. Zenz M, Willweber-Strumpf A. Opiophobia and cancer pain in Europe. Lancet Lond Engl. (1993) 341:1075-6. doi: 10.1016/0140-6736(93)92425-S

44. Bennett DS, Carr DB. Opiophobia as a barrier to the treatment of pain. J Pain Palliat Care Pharmacother. (2002) 16:105-9. doi: 10.1080/J354v16n01_09

45. Tsui JI, Lira MC, Cheng DM, Winter MR, Alford DP, Liebschutz JM, et al. Chronic pain, craving, and illicit opioid use among patients receiving opioid agonist therapy. Drug Alcohol Depend. (2016) 166:26-31. doi: 10.1016/j.drugalcdep.2016.06.024

46. Compton P, Charuvastra VC, Kintaudi K, Ling W. Pain responses in methadone-maintained opioid abusers. J Pain Symptom Manage. (2000) 20:237-45. doi: 10.1016/S0885-3924(00)00191-3

47. Doverty M, White JM, Somogyi AA, Bochner F, Ali R, Ling W. Hyperalgesic responses in methadone maintenance patients. Pain (2001) 90:91-6. doi: 10.1016/S0304-3959(00)00391-2

48. Hay JL, White JM, Bochner F, Somogyi AA, Semple TJ, Rounsefell B. Hyperalgesia in opioid-managed chronic pain and opioid-dependent patients. J Pain Off J Am Pain Soc. (2009) 10:316-22. doi: 10.1016/j.jpain.2008.10.003

49. Compton WM, Boyle M, Wargo E. Prescription opioid abuse: problems and responses. Prev Med. (2015) 80:5-9. doi: 10.1016/j.ypmed.2015.04.003

50. Shei A, Rice JB, Kirson NY, Bodnar K, Birnbaum HG, Holly P, et al. Sources of prescription opioids among diagnosed opioid abusers. Curr Med Res Opin. (2015) 31:779-84. doi: 10.1185/03007995.2015.1016607

51. Rudd RA, Aleshire N, Zibbell JE, Gladden RM. Increases in drug and opioid overdose deaths-united states, 2000-2014. MMWR Morb Mortal Wkly Rep. (2016) 64:1378-82. doi: 10.15585/mmwr.mm6450a3

52. Centers for Disease Control and Prevention Wide-ranging online data for epidemiologic research (WONDER). Atlanta, GA: CDC, National Center for Health Statistics. Available online at: https://wonder.cdc.gov/ (Accessed July 7, 2017) (2016).

53. Manhapra A, Rosenheck R, Fiellin DA. Opioid substitution treatment is linked to reduced risk of death in opioid use disorder. BMJ (2017) 357:j1947. doi: 10.1136/bmj.j1947

54. Savage SR, Kirsh KL, Passik SD. Challenges in using opioids to treat pain in persons with substance use disorders. Addict Sci Clin Pract. (2008) 4:4-25. doi: 10.1151/ascp08424

55. Volkow ND, McLellan AT. Opioid abuse in chronic pain - misconceptions and mitigation strategies. $N$ Engl J Med. (2016) 374:1253-63. doi: 10.1056/NEJMra1507771

56. Wallwork RS, Chipidza FE, Stern TA. Obstacles to the prescription and use of opioids. Prim Care Companion CNS Disord. (2016) 18. doi: 10.4088/PCC.15f01900

57. Barry DT, Beitel M, Joshi D, Schottenfeld RS. Pain and substance-related painreduction behaviors among opioid dependent individuals seeking methadone maintenance treatment. Am J Addict Am Acad Psychiatr Alcohol Addict. (2009) 18:117-21. doi: 10.1080/10550490902772470

58. Trafton JA, Oliva EM, Horst DA, Minkel JD, Humphreys K. Treatment needs associated with pain in substance use disorder patients: implications for concurrent treatment. Drug Alcohol Depend. (2004) 73:23-31. doi: 10.1016/j.drugalcdep.2003.08.007

59. Hardt J, Jacobsen C, Goldberg J, Nickel R, Buchwald D. Prevalence of chronic pain in a representative sample in the United States. Pain Med Malden Mass (2008) 9:803-12. doi: 10.1111/j.1526-4637.2008.00425.x

60. Kennedy J, Roll JM, Schraudner T, Murphy S, McPherson S. Prevalence of persistent pain in the U.S. adult population: new data from the 2010 national health interview survey. J Pain Off J Am Pain Soc. (2014) 15:979-84. doi: 10.1016/j.jpain.2014.05.009

61. Riskowski JL. Associations of socioeconomic position and pain prevalence in the United States: findings from the National Health and Nutrition
Examination Survey. Pain Med Malden Mass (2014) 15:1508-21. doi: $10.1111 /$ pme. 12528

62. Nosyk B, Fischer B, Sun H, Marsh DC, Kerr T, Rehm JT, et al. High levels of opioid analgesic co-prescription among methadone maintenance treatment clients in British Columbia, Canada: results from a populationlevel retrospective cohort study. Am J Addict. (2014) 23:257-64. doi: 10.1111/j.1521-0391.2014.12091.x

63. Inacio MCS, Hansen C, Pratt NL, Graves SE, Roughead EE. Risk factors for persistent and new chronic opioid use in patients undergoing total hip arthroplasty: a retrospective cohort study. BMJ Open (2016) 6:e010664. doi: 10.1136/bmjopen-2015-010664

64. Braveman PA, Cubbin C, Egerter S, Williams DR, Pamuk E. Socioeconomic disparities in health in the United States: what the patterns tell us. Am J Public Health (2010) 100:S186-96. doi: 10.2105/AJPH.2009.166082

65. Grol-Prokopczyk H. Sociodemographic disparities in chronic pain, based on 12-year longitudinal data. Pain (2017) 158:313-22. doi: $10.1097 /$ j.pain.0000000000000762

66. Henkel D. Unemployment and substance use: a review of the literature (1990-2010). Curr Drug Abuse Rev. (2011) 4:4-27. doi: 10.2174/1874473711104010004

67. Barkhuizen A, Rosen HR, Wolf S, Flora K, Benner K, Bennett RM. Musculoskeletal pain and fatigue are associated with chronic hepatitis C: a report of 239 hepatology clinic patients. Am J Gastroenterol. (1999) 94:1355-60. doi: 10.1016/S0002-9270(99)00143-4

68. Silberbogen AK, Janke EA, Hebenstreit C. A closer look at pain and hepatitis C: preliminary data from a veteran population. J Rehabil Res Dev. (2007) 44:231-44. doi: 10.1682/JRRD.2006.05.0053

69. Tsui JI, Herman DS, Kettavong M, Anderson BJ, Stein MD. Chronic pain and hepatitis $\mathrm{C}$ virus infection in opioid dependent injection drug users. J Addict Dis. (2011) 30:91-7. doi: 10.1080/10550887.2011.554775

70. Larance B, Campbell G, Peacock A, Nielsen S, Bruno R, Hall W, et al. Pain, alcohol use disorders and risky patterns of drinking among people with chronic non-cancer pain receiving long-term opioid therapy. Drug Alcohol Depend. (2016) 162:79-87. doi: 10.1016/j.drugalcdep. 2016.02.048

71. Zale EL, Maisto SA, Ditre JW. Interrelations between pain and alcohol: An integrative review. Clin Psychol Rev. (2015) 37:57-71. doi: 10.1016/j.cpr.2015.02.005

72. Braden JB, Sullivan MD, Ray GT, Saunders K, Merrill J, Silverberg MJ, et al. Trends in long-term opioid therapy for noncancer pain among persons with a history of depression. Gen Hosp Psychiatry (2009) 31:564-70. doi: 10.1016/j.genhosppsych.2009.07.003

73. Cowan DT, Wilson-Barnett J, Griffiths P, Allan LG. A survey of chronic noncancer pain patients prescribed opioid analgesics. Pain Med Malden Mass (2003) 4:340-51. doi: 10.1111/j.1526-4637.2003.03038.x

74. Sullivan MD, Edlund MJ, Fan MY, Devries A, Brennan Braden J, Martin BC. Risks for possible and probable opioid misuse among recipients of chronic opioid therapy in commercial and medicaid insurance plans: The TROUP Study. Pain (2010) 150:332-9. doi: 10.1016/j.pain.2010.05.020

75. Dunn KM, Saunders KW, Rutter CM, Banta-Green CJ, Merrill JO, Sullivan MD, et al. Opioid prescriptions for chronic pain and overdose: a cohort study. Ann Intern Med. (2010) 152:85-92. doi: 10.7326/0003-4819-152-2-201001190-00006

76. Edlund MJ, Martin BC, Devries A, Fan MY, Braden JB, Sullivan MD. Trends in use of opioids for chronic noncancer pain among individuals with mental health and substance use disorders: the TROUP study. Clin J Pain (2010) 26:1-8. doi: 10.1097/AJP.0b013e3181b99f35

77. Grattan A, Sullivan MD, Saunders KW, Campbell CI, Von Korff MR. Depression and prescription opioid misuse among chronic opioid therapy recipients with no history of substance abuse. Ann Fam Med. (2012) 10:30411. doi: $10.1370 / \mathrm{afm} .1371$

78. Dennis BB, Bawor M, Naji L, Chan CK, Varenbut J, Paul J, et al. Impact of chronic pain on treatment prognosis for patients with opioid use disorder: a systematic review and meta-analysis. Subst Abuse Res Treat. (2015) 9:59-80. doi: 10.4137/SART.S30120

79. Buckley PF. Prevalence and consequences of the dual diagnosis of substance abuse and severe mental illness. J Clin Psychiatry (2006) 67 (Suppl. 7):5-9. doi: 10.4088/JCP.0706e 01 
80. Drake RE, Mercer-McFadden C, Mueser KT, McHugo GJ, Bond GR. Review of integrated mental health and substance abuse treatment for patients with dual disorders. Schizophr Bull. (1998) 24:589-608. doi: 10.1093/oxfordjournals.schbul.a033351

81. Kurdyak P, Gomes T, Yao Z, Mamdani MM, Hellings C, Fischer B, et al. Use of other opioids during methadone therapy: a population-based study. Addict Abingdon Engl. (2012) 107:776-80. doi: 10.1111/j.1360-0443.2011.03707.x

82. Landmark T, Romundstad P, Borchgrevink PC, Kaasa S, Dale O. Associations between recreational exercise and chronic pain in the general population: evidence from the HUNT 3 study. Pain (2011) 152:2241-7. doi: 10.1016/j.pain.2011.04.029
Conflict of Interest Statement: The authors declare that the research was conducted in the absence of any commercial or financial relationships that could be construed as a potential conflict of interest.

Copyright ( 2018 Delorme, Chenaf, Bertin, Riquelme, Eschalier, Ardid and Authier. This is an open-access article distributed under the terms of the Creative Commons Attribution License (CC BY). The use, distribution or reproduction in other forums is permitted, provided the original author(s) and the copyright owner(s) are credited and that the original publication in this journal is cited, in accordance with accepted academic practice. No use, distribution or reproduction is permitted which does not comply with these terms. 